\title{
Er/Pr-codoped borotellurite glasses as efficient laser operated nonlinear optical materials
}

\begin{abstract}
We have discovered a rare opportunity to operate by the SHG at fundamental wavelength $10.6 \mu \mathrm{m}$ of microsecond $\mathrm{CO} 2$ laser during simultaneous irradiation by $1064 / 532 \mathrm{~nm}$ bicolor laser beams of (60-x-y)TeO2-10B2O3-10BaO-10ZnO-10Na2O(x)Er2O3-(y)Pr6O11 $(\mathrm{x}=0.5, \quad 1.0 ; \mathrm{y}=0) ; \quad(\mathrm{x}=0 ; \mathrm{y}=0.1, \quad 0.2, \quad 0.3,0.4,0.5)$; $(\mathrm{x}=0.5,1.0 ; \mathrm{y}=0.1,0.2,0.3,0.4,0.5)(\mathrm{mol} \%)$ glasses. The effect has shown a drastic sensitivity of the effect to the Er/Pr ratio. The effect exists only during the simultaneous illumination and applied dc-electric field at $5 \mathrm{kV} / \mathrm{cm}$. Only completely reversible changes were observed. The effect is a consequence of photopolarization during the bicolor coherent laser beams and its efficiency is determined by the transfer of excitation between the Er and Prions.
\end{abstract}

Keyword: Borotellurite glass; Er3+; Pr3+; XRD; TGA; Bicolor laser treatment 